\title{
Three stage Toll Gate Alarming Mechanism on Road Highways
}

\author{
K. Vidyasagar \\ Department of ECE, SSIT \\ Sathupalli, T.S, India
}

\author{
K. Swathi \\ Department of ECE, SSIT \\ Sathupalli, T.S, India
}

\author{
K. Sudharsanarao \\ Department of ECE, SSIT \\ Sathupalli, T.S, India
}

\begin{abstract}
National highway road security is challenging with increase of terrorist attacks across the world. The shipment of payload materials and illegal weapons in containers and even transport cars is a significant component to deliberate in modern days. This paper focused on three stage toll gate security system to automate the security level at targeted toll gates on road highways. X-ray scanning mechanism is proposed at stage 1 to scan the hidden objects. Back scattered X-ray method is applied to improve the scan process. Capacitive stretch sensor technology is proposed to weigh the moving vehicle. The capacitive sensitivity is increased with three electrode layers. Radio frequency technology is proposed for toll management system. Global System for mobile communication is implanted for communicate with toll amount information, Overload state of the vehicle, weapons and explosive information to the pre defined destination locations. The proposed methodology is reliable to safeguard the human life and to alert the security agencies from the terrorist movements in road highways.
\end{abstract}

\section{Keywords}

X-radiation energy, Stretch Sensor, RFID,GSM.

\section{INTRODUCTION}

Security to the nation is a challenging task with the advancement of anti social element power. Terrorist attacks are growing in a rapid manner with advanced technology. The shipment of explosive materials in road way is a big challenge to the security agencies. The manual security verification process is dominated by external influences, tiredness of the security officers, and improper checking of the vehicle may leads to significant damage to the nation. Automation of the security process is desirable to alert the authorities before the miserable incidence take place.

Three stage security mechanisms at targeted toll plaza are proposed in this paper. The process is decomposed into Payload, explosives and weapons detection stage, over weight detection stage, and Toll management stage. Every vehicle should clear the three stages. The back scattered X-ray source is applied at stage 1 to detect the payload and weapons shipment in a container. The thickness of the container is considered to penetrate the X-radiation energy in order to trace the hidden objects. Maximum of ' 9 ' mega electron volts energy source is proposed to penetrate into any material. ' 2 ' $\mathrm{MeV}$ x-ray energy can penetrate into $62.23 \mathrm{~mm}$ thickness of the concrete materials. Even though the weapons shielded with concrete material can detect with ' 9 ' $\mathrm{MeV}$ X-ray energy. The container loaded with the identified illegal weapons cause to communicate the nearby police control room using Global system for mobile communication (GSM) and the bugler alarm at the police control room will be ' $\mathrm{ON}$ ' to enable the security process. The exit gate will be open only when the $\mathrm{X}$ ray image is normal. Otherwise the gate is closed.
Stretch sensor technology is adopted at the stage ' 2 ' to measure the overload state of the moving vehicle. Each vehicle weight is tabulated with no load and full load status. If the vehicle is moving with overload state the vehicle information is automatically transmitted to the road transport authority and nearby police control room using GSM. The second exit gate open state at stage two depends on the full load moving vehicle within the permitted limits.

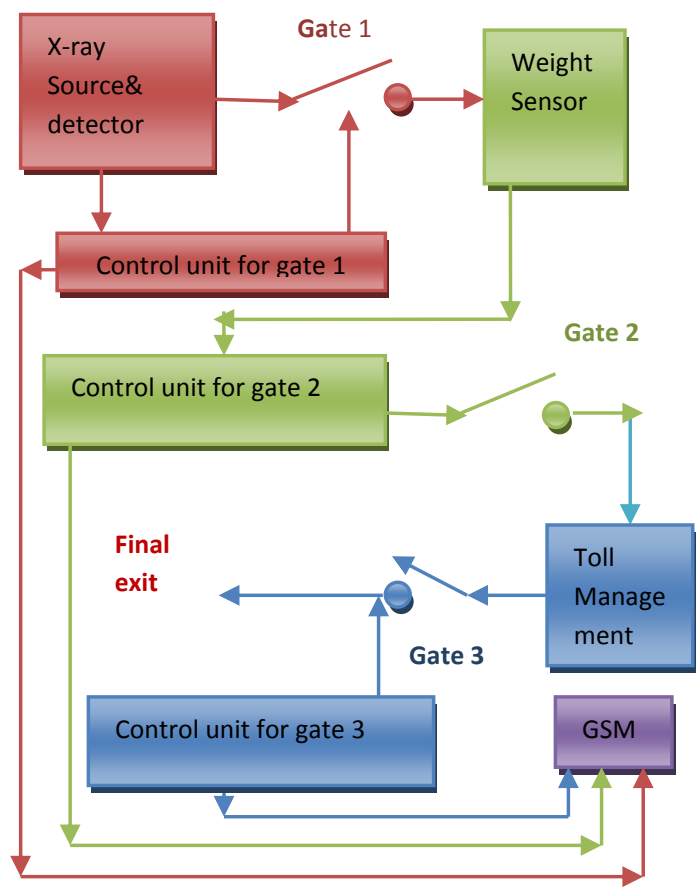

Fig1.1 Architecture of the three stage Toll gate alarming system on road Highways.

The overload vehicle is directed to clear the security pass and forced to keep in wait state at specified location. Fig 1.1 explains the architecture of the proposed methodology.

Radio frequency (RF) Technology is adopted to manage the toll amount. The registered vehicles can move freely at the stage three after clearing the security pass at both stage ' 1 'and stage ' 2 '

\section{LITERATURE SURVEY}

\subsection{Relevant work in Toll collection management}

Venkatesh Suvarna, discussed RFID based highway toll control system in paper [1]. Different micro controllers are used to regulate the process. 
Instead of RFID the paper [2] deliberated the Zigbee transceiver in order to increase the communication range. This methodology is adopted to curtail the manual toll collection and operation cost. In [3][4][5][7][9][10] proposed a mechanism to toll collection. The pre charged toll amount will be reduced for every entry and the negative balance will be alarmed to the vehicle owner. These papers did not be provided any novelty in presentation. The author concluded, as car is passing through the RFID reader the toll amount is deducted accordingly. The fuel consumption is to be saved without slow down the speed of the vehicle. But In practical the RFID reader is not able to detect the authorized tag without slow down the speed of the vehicle. And also the distance between the reader and the tag should be close each other.

S.Nandhini, P.Premkumar, in [6] proposed a methodology using IR transceiver for highway toll free collection system. Global system for mobile communication (GSM) is adopted to communicate the amount deduction status to the vehicle authorized person

In [11], a methodology is proposed to record the theft vehicle identification in association with RFID based toll collection system.

In [12] bar code based toll collection system is proposed. Vehicle registration, tracking and theft vehicle identification system is proposed in this paper. AungMyint Win et.al in [13] proposed a Graphical user interface based vehicle registration process and RFID based vehicle toll management system.

\subsection{Relevant work on hidden objects imaging}

In paper [14] visual inspection tool is proposed to identify the hidden explosive objects in the containers. Luggage line scanner is discussed for luggage checking. X-ray diffraction methodology is discussed for identifying the crystal structures. Compton back scattered method is discussed for landmines and for explosive devices.

In [15] described a mechanism for detecting the dangerous materials and illicit objects. The physical background and their advantages and limitations with the existing systems are analyzed. Considering the enhanced threat of terrorist attacks

Paper [16] proposed a methodology to detect the hidden objects in aluminum containers using back scattered ultraintense laser -produced $\mathrm{x}$-rays. The shapes of the objects are revealed by using the backscattering phenomena. Using energy spectra of backscattered X-rays the material composition is also can be identified.

\subsection{Relevant work in Weight measurement}

Electrical Strain gauge weight pads are applied in [17] for weight measurement and in node data processing. Wireless communication is developed by Capacitive based weight measuring system is proposed in [18] to measure the weight of the vehicle. The voltage output of the capacitive load sensor is interfaced to the personal computer using Rs-232 serial communication protocol. Paper [19] mounted Bending and load cell plates on the road. In order to get full type imprint on the scale at once, the load cell extent is longer than type imprint. The load applied on the capacitive type of film sensors in both axial and longitudinal directions are discussed in [20 in order to improve the sensitiveness in the measurement.

\section{DESIGN CONSIDERATIONS}

Short wavelength high energy electromagnetic wave (X- Ray) is able to pass through different materials opaque to light. Xray imaging creates pictures inside the container. The image represents different shades of black and white corresponding to the objects of the container. Different materials will absorb different amounts of radiation.

X-ray contrasts of the objects depend on the type of the material. The contrast did not depend on the thickness of the material. For discriminating between different materials the Hounsfield unit (HU) or absorption coefficient is used. 'HU' for air is -1000 , for water ' 0 ' and for metals' -2000 '. But fruit cake, cheese and plastic explosives have similar absorption coefficients. So, X-ray diffraction patterns are recommended to differentiate the micro crystalline materials. Majority of the explosives are crystalline substances.

The big containers walls are made of with 3.2 to $6.4 \mathrm{~mm}$ thickness. In order to image the material inside the container the X-ray beam energy will play a vital role. Since the X-ray absorption coefficient is dependent on the energy of the X-ray beam. For scanning high energy mega-electron volts X-ray sources are required for container wall penetration. For penetrating $300 \mathrm{~mm}$ thickness of the container wall approximately ' 9 ' Mev x-ray energy is required. The Xradiation energy depth of penetration is related with various materials represented in table 3.1 .

Table 3.1 X- Radiation energy Vs depth of penetration of the material.

\begin{tabular}{|l|l|l|}
\hline Energy $(\mathrm{K} \mathrm{eV})$ & Lead $(\mathrm{mm})$ & Concrete $(\mathrm{mm})$ \\
\hline 50 & 0.06 & 4.32 \\
\hline 100 & 0.27 & 15.10 \\
\hline 200 & 0.52 & 25.00 \\
\hline 300 & 1.47 & 31.21 \\
\hline 400 & 2.50 & 33.00 \\
\hline 1000 & 7.90 & 44.45 \\
\hline 2000 & 9.98 & 62.23 \\
\hline
\end{tabular}

Back scatter X-ray imaging is used to find the explosive materials in the container meticulously. The proposed system is represented in fig 3.1. The primary collimator moves in the plane towards the object for different depths of the container in both ' $x$ ' and ' $y$ ' direction. To obtain good images, the photons from the X-ray source moving towards the object and the back scattered signal from the container need to be detected.

More back scatter is detected for explosive materials than plastic materials. The x-ray imaging is used to harvest the images of the hidden objects inside the container. The X-ray image consists of grey and white matter. The intensity of the pixel elements of the image representing the type of the material it is. The Segmentation and clustering analysis is adopted to discriminate the explosive materials from the non explosive materials. Discriminating the objects inside the container higher resolution is required.

\subsection{Image intensification}

The harvested X-ray image resolution is enhanced using the combination of discrete wavelet transform (DWT) and stationary wavelet transform (SWT). For image intensification, bi-cubic interpolation is applied to harvest smooth surface.. Information loss is arising on its edges. i.e. at high frequency components. DWT is adopted to safeguard the edge information. The coefficients of the DWT are interpolated to harvest the shift invariance. X-ray image is 
disintegrated into LH, HL, HH Sub band images. In view of down sampling the information loss is to be negotiated by adopting the SWT. The high frequency sub bands of SWT and interpolated high frequency sub bands are added each other.
The authentic high resolution input image is having admirable information than low frequency sub bands. Hence the interpolation is again applied on the input X-Ray image Low frequency sub bands [7] [8]

Further resolution is harvested by interpolating the estimated High frequency sub bands. The high resolute images are having significant information than low frequency sub bands.

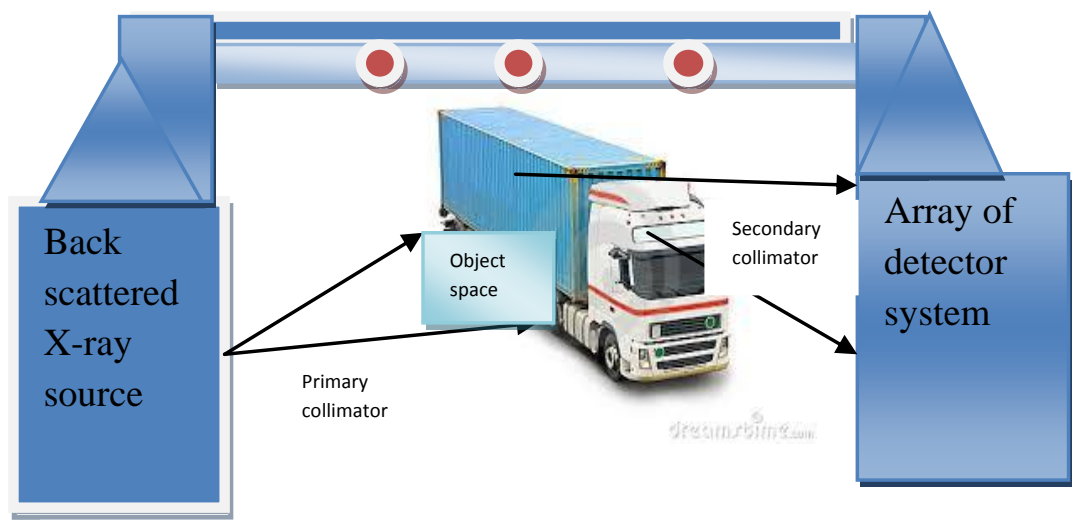

Fig3.1 Compton back scatters system for detecting the explosives

\subsection{Weight measuring system}

Dynamic Loads can be measured using weight in motion sensors. The capacitive mats, bending plates, load cells and piezoelectric sensors are more relevant to measure the vehicle load.

Table 3.2 Car allowed weight chart (Type 1)

\begin{tabular}{|l|l|l|}
\hline Car model & $\begin{array}{l}\text { No load weight } \\
\text { (Kg) } \\
\text { Vehicle kerb } \\
\text { weight }\end{array}$ & $\begin{array}{l}\text { Full load } \\
\text { weight } \\
\text { Kg) } \\
\text { Kerb } \\
\text { weight + } \\
\text { Driver + 4 } \\
\text { persons @ } \\
\mathbf{7 2 K g}\end{array}$ \\
\hline Volkswagen polo 1.4 & 1070 & 1430 \\
\hline Skoda Fabio 1.6 & 1100 & 1360 \\
\hline Honda Brio & 920 & 1280 \\
\hline Swift & 960 & 1320 \\
\hline Toyota Etios & 890 & 1250 \\
\hline Hundai i20 & 1155 & 1515 \\
\hline Hundai i10 1.2 kappa & 996 & 1356 \\
\hline Chevrolet beat & 1020 & 1380 \\
\hline Ford Figo & 1040 & 1400 \\
\hline
\end{tabular}

Stretch sensor technology is adopted to measure the vehicle weight in motion. About $100 \mu \mathrm{m}$ thin elastomeric film coated on both sides with stretchable electrode layers. When a load is applied the elastomeric film is stretched in more dimensions, the film thickness is decreased and eventually increases the electrode surface.
Table 3.3 Transport vehicle weight chart (Type2)

\begin{tabular}{|c|c|}
\hline Transport vehicle model & $\begin{array}{l}\text { Maximum Grass } \\
\text { vehicle alowed } \\
\text { weight (tonns) }\end{array}$ \\
\hline $\begin{array}{l}\text { Two Axle Tractor } \\
\text { Single Axle Trailer } \\
\text { Tractor: } 2 \text { Wheels on front axle } 4 \\
\text { Wheels on rear axle, Trailer: } 4 \\
\text { Wheels on single axle }\end{array}$ & 26.4 \\
\hline $\begin{array}{l}\text { Three Axle Tractor } \\
\text { Single Axle Trailer } \\
\text { Tractor: } 2 \text { Wheels on front axle } 8 \\
\text { Wheels on rear axle, Trailer: } 8 \\
\text { Wheels on single axle }\end{array}$ & 35.2 \\
\hline $\begin{array}{l}\text { Two Axle Truck } \\
\text { Two Axle Trailer } \\
\text { Truck: } 2 \text { Wheels on front axle } \\
\text { 4Wheels on rear axle, Trailer: } 4 \\
\text { Wheels on front axle, } 4 \text { Wheels on } \\
\text { rear axle }\end{array}$ & 36.6 \\
\hline $\begin{array}{l}\text { Three Axle Truck } \\
\text { Three Axle Trailer } \\
\text { Truck: } 2 \text { Wheels on front axle, } 4 \\
\text { Wheels on rear axle } \\
\text { Trailer: } 4 \text { Wheels on rear axle }, 8 \\
\text { Wheels on rear tandem axle }\end{array}$ & $\begin{array}{l}45.4 \text { (restricted to } \\
44.0 \text { tonnes }\end{array}$ \\
\hline $\begin{array}{l}\text { Three Axle Truck } \\
\text { Three Axle Trailer } \\
\text { Truck: } 2 \text { Wheels on front axle ,8 } \\
\text { Wheels on rear tandem axle, } \\
\text { Trailer: } 4 \text { Wheels on front axle, } 8 \\
\text { Wheels on rear tandem axle }\end{array}$ & $\begin{array}{l}54.2 \text { (restricted to } \\
44.0 \text { tonnes) }\end{array}$ \\
\hline
\end{tabular}

This results the enhancement of capacitance between the electrodes. According to suggestions drafted by 'Holder Bose' in order to increase the capacitance sensitivity both in the 
axial and longitudinal forces, the film contains three electrode layers.

Two outer layers are connected to the ground potential. Across the inner and outer layers the capacitance is measured in terms of voltage signal. This signal is interfaced to the computer to estimate the overload state of the vehicle. Maximum allowed load of each vehicle is labeled as set point (SP) value. The measured load is compared with the Set point value. The maximum error value ( $\mathrm{SP}-\mathrm{PV}$ ) is considered as an abnormal load which is communicated to the nearby police station and to the registered road transport officer (RTO) in the form of message by adopting the Global System for Mobile Communication Technology (GSM). The message housed with the vehicle number, type of vehicle, and Overload state of the moving vehicle.

\subsection{Toll collection management system}

Rechargeable radio frequency identification card is used for the registered vehicles. To determine the validity of the card an RFID reader is equipped at the gate. The RF ID tag with the moving vehicle validity is verified to open and close the toll gate. The code is verified with the database. If match is found then the toll amount will be automatically detected and is based on the mode of deduction. Two modes of deductions are applicable for this process. Mode' 1 ' is one way travel. One time amount will be deducted. Mode 2 is two way travels. Twice the amount will be deducted. The state of the deduction and the remaining balance amount message will be transmitted to the vehicle owner mobile, using the global system for mobile communication (GSM). ARM processor is used to regulate the toll management system. The RFID reader will communicate the information to the ARM processor serially using MAX 232.

\section{PROPOSED METHODOLOGY Algorithm 1}

Step 1: Capture the vehicle image

Step2: determine the vehicle model and type

Step3: Enable the X-ray energy source

Step4: If the vehicle is type ' 1 '

Then adjust the X-radiation energy to ' 50 ' $\mathrm{KeV}$

Else for type ' 2 ' vehicles

Adjust the X-radiation to ' 9 ' $\mathrm{MeV}$

Then capture the X-Ray image

Step5: Estimate the Global threshold value

Step6: Normalize the input image into $256 * 256$ sizes

Step7: Convert the image into double precision values

Step8: reshape the image into datasets of column vector for segmentation

Step9: determine the number of clusters i.e centroids.

Step10: Estimate the distance between input vehicle data set points and set points of the centroids.

Step11: find the data set points which are neighbouring to the centroid

Step12: Select the centroid with minimum distance, and then move the data set points to the closest relevant centroid
Step 13: Re compute the centroid by selecting the maximum pixel value from the set of relevant centroid data points.

Step 14: Repeat this process until the new and previous centroids are identical

Step15: Allocate the membership values $-1,0$ and 1 to each pixel of the cluster centroids

Step16: Apply the binary decision on the segmented image to obtain the final cluster image $\mathrm{g}(\mathrm{n})$

Step17: Apply the classifier algorithm to detect the weapon

Step18: If the image contains weapons and pay loads

Then Close the gate ' 1 '

Else open the gate and go to Algorithm 2

Algorithm2:

Step1: Initialize the lookup table for type 1

And for type 2

Step2: Measure the weight of the vehicle

Step3: if

The weight is $\leq 3$ ton

Then compare with type 1 lookup table

Else compare with type 2 lookup table

Step4: if

The weight is within regulated limit

Then open the exit gate ' 2 '

Else enable the GSM send the message signal and

Enable the bugler alarm Gate ' 2 ' is closed.

Step5: Displays the result and go to Algorithm 3

Algorithm 3:

Step1: Reset the device

Step2: Initialize the RF reader

Step3: initialize the GSM module

Step4: Register the mobile numbers

Create the database

Step5: Equate the mobile numbers with the RFID tag

Step3: Scan the vehicle RFID tag

Step4: if the vehicle is registered

Then

Scan for the relevant RFID tag associated with mobile number.

If the scan is true

Then

Determine the mode, and go to next step

Else insert algorithm ' $x$ '

Step5: if

Mode is ' 1 ' 


\section{Then subtract one time amount}

Else for mode 2

\section{Subtract two time amount}

Step6: Enable the GSM

Step7: Send the subtracted value and the balance value to the authorized mobile number.

Step8: Open the exit gate ' 3 '.

Step9: go to step1.

\section{Algorithm x}

Step1: register the vehicle

\section{Go to step1}

\section{RESULTS}

For toll collection management system used EM18 RFID reader. The coils with in EM18 will radiate $125 \mathrm{KHz}$. The passive RFID tag with $125 \mathrm{KHz}$ will be energized when it is close to this field. The CMOS IC EM4102 within RFID tag will get enough power to reach the energy radiated by the reader. It have been observed that with EM18 RFID reader detect the tag only when it is close to an approximation of ' 6 ' $\mathrm{cm}$ distance. For real applications this kind of RFID is not appropriate. Hence MTUHF-Long range RFID card reader operating at 865 to $868 \mathrm{MHz}$ frequency is proposed for multivehicle tracking within the area of $12 \mathrm{~m}$ from the vehicle. The quick and multi tag reading will enable to read the passive RFID tag when the vehicle in motion.

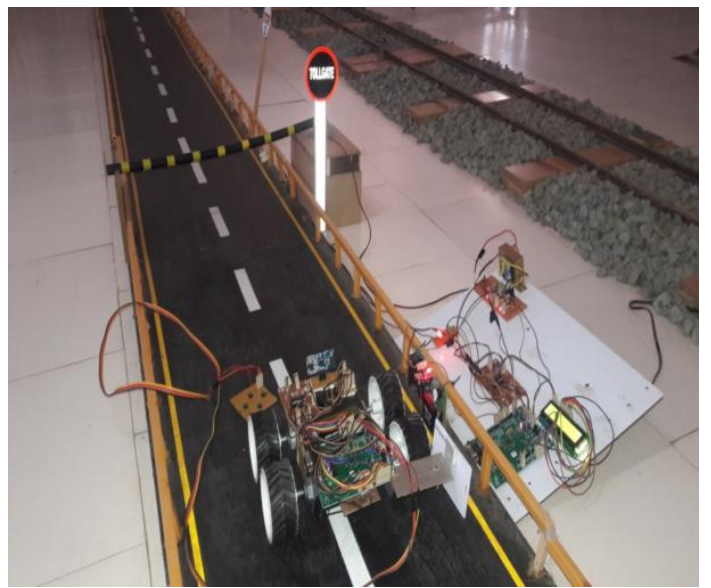

Fig 5.1 Developed model of the toll gate in closed state

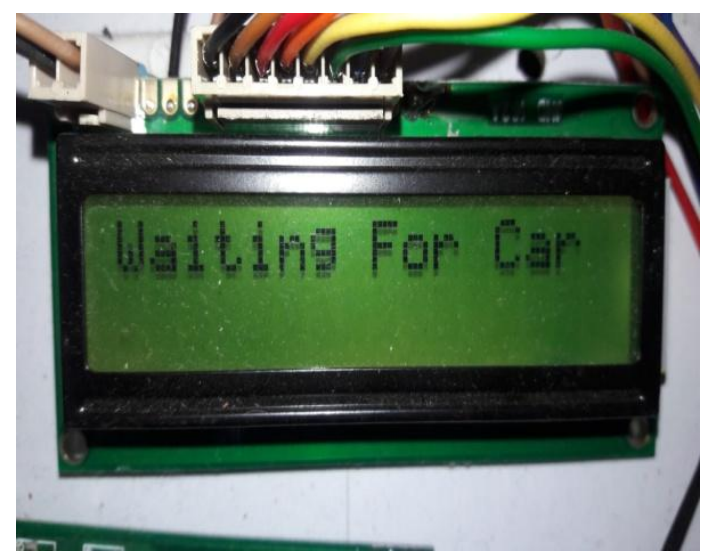

Fig 5. 2 Display status before the vehicle authorization

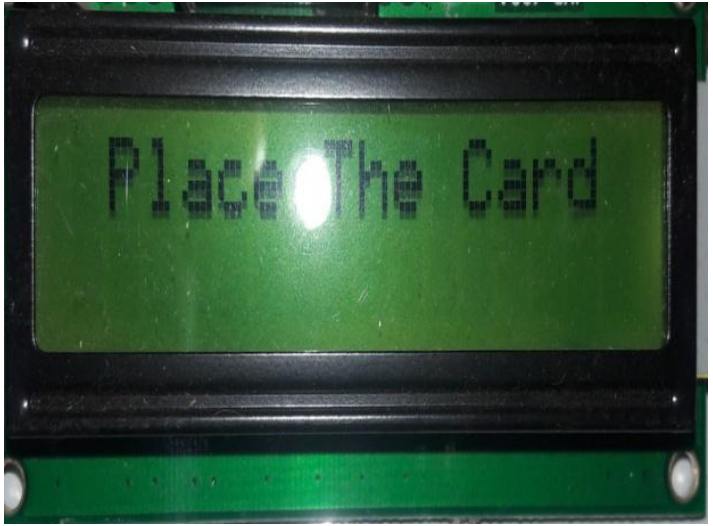

Fig 5.3 Display status while detecting the vehicle

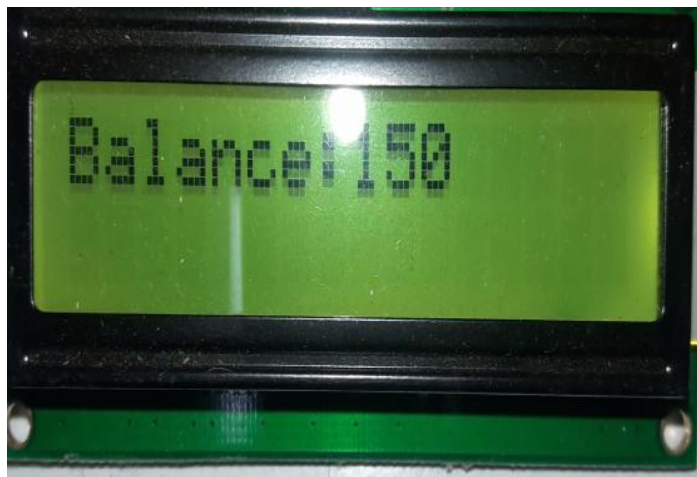

Fig 5.4. Display status after authorization

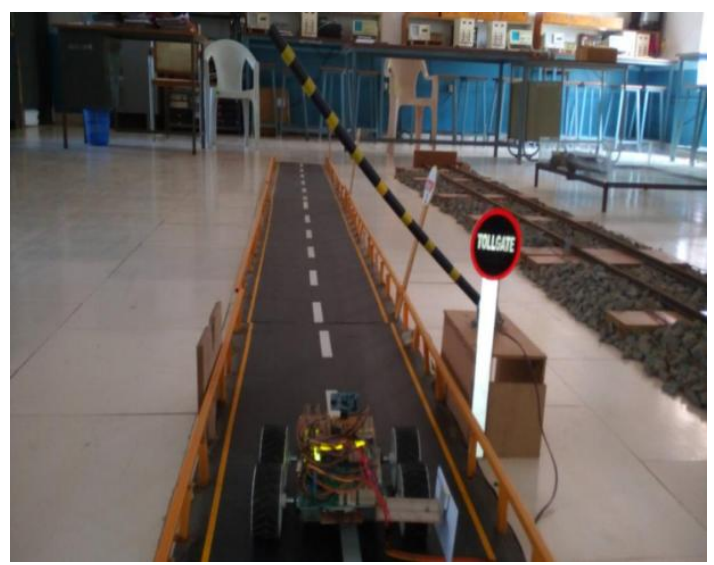

Fig 5.4 Toll gate open after the RF validity is verified

Fig 5.1 represents the initial status of the toll gate mechanism. In order to open the gate the vehicle is to be verified with the RFID reader. The RFID tag housed with the vehicle should be detected by the RFID reader. Fig 5.3 and Fig 5.4 represents the status of the vehicle to readjust the pre paid toll amount. The balance amount will be displayed at the toll control room and the same will be transferred to the vehicle owner using Global system for mobile communication.

\section{CONCLUSION}

The proposed methodology is having valued importance to the nations. The anti social movements and the shipment of the payloads and weapons on road ways can be curtailed by deliberating the proposed methodology. The X-ray energy source from $50 \mathrm{~K} \mathrm{ev}$ to $2 \mathrm{Mev}$ are considered to penetrate the $\mathrm{x}$-radiation for various thickness materials of the vehicle. For improving the analysis of the extracted image, super resolute image methodology is adopted with the support of Discrete 
and stationary wavelet transforms. This approach results favorable images for analysis. This is labeled as stage 1 process. Table 3.2 and table 3.3 summarize the type 1 vehicle as car and type 2 vehicle as transport vehicle. The data base is generated for verifying the overload state of the type land type 2 vehicles. This is labeled as stage 2. The toll gate management is labeled as Stage 3. This three stage process will safeguard the nation's properties and the human life from anti social activities. The proposed methodology is recommended at specific locations in order to harvest better results

\section{ACKNOWLEDGEMENT}

The authors express the deep sense of gratitude to the management and principal of Sai spurthi institute of Technology for providing the necessary infrastructure and funding.

\section{REFERENCES}

[1] Venkatesh Suvarna, Jeet Patalia," A Review on Various RFID Based AutomatedHighway Toll Collection Systems", International Journal of Computer Science and Information Technologies, Vol. 6 (3): 2130-2133, 2015.

[2] Surendra S. Dalu, "an automated electronic toll collection using zigbee" , International Journal of Information Technology and Knowledge Management, Volume 5, No. 1, pp. 1-3, January-June 2012.

[3] Pranoti Salunke,et.al, "Automated Toll Collection System Using RFID", Journal of Computer Engineering, Vol. 9( 2): PP 61-66, Jan. - Feb. 2013.

[4] T. Arun Prasath, M.S.Dhanabal," Automated Toll Gate System Using RFID And GSM Technology, International Journal of Science and Research, Vol. 4(2): 497-500, Feb 2015.

[5] Aniruddha Kumawat, Kshitija Chandramore, "automatic toll collection system using RFID”, International Journal of Electrical and Electronics Research, Vol.2 92): 67-72, April-June 2014

[6] S. Nandhini, P. Premkumar, "Automatic Toll Gate System Using Advanced RFID and GSM Technology", International Journal of Advanced Research in Electrical, Electronics and Instrumentation Engineering, Vol. 3(11): 13002- 13007 November 2014.

[7] Sudha Bhalekar, Adesh Chanageri G, Indra Prakash Chauhan, "Automatic Toll Tax Using RFID", International Journal of Computer Technology and Electronics Engineering, Vol. 3: 4-8, March-April 2013.

[8] Sudha Bhalekar, et.al," Automatic toll tax using RFID", International Journal of Computer Technology and Electronics Engineering, Vol.3:4-8, March-April 2013.

[9] M. Sumithra and B. Buvaneswari, "Computerized toll collection system using smart card with RFID", Journal of Engineering and Applied Sciences, VOL. 10(21): 9958-9961 November, 2015.

[10] Khadijah kamarulazizi, widad ismail," Electronic toll collection system using passive rfid technology", Journal of Theoretical and Applied Information Technology, 2005-2010.

[11] Amol A. Chapate, D.D. Nawgaje," Electronic Toll Collection System Based on ARM", International
Journal of Science, Engineering and Technology Research, Vol.4 (1): January 2015.

[12] Devika Mhatre, "Electronic Toll Collection Using Barcode Reader", International Journal of Advanced Research in Computer Science and Software Engineering, Vol.5 (2): 124-127, February 2015.

[13] AungMyint Win,et.al, "RFID based automated toll plaza system", International Journal of Scientific and Research Publications, Vol.4(6): 1-7 June 2014.

[14] George Zentai, "X-ray Imaging for Homeland Security", IEEE International Workshop on Imaging Systems and Techniques - IST, Chania, Greece, September 10-12, 2008.

[15] Yuri Melnikov,et.al, "Detection of Dangerous Materials and Illicit Objects in Cargoes and Baggage: Current Tools, Existing Problems and Possible Solutions", Journal of homeland security and emergency management, Vol.8 (1): 2011.

[16] H. Kuwabara, Y.Mori, Y. kitagawa, "Standoff detection of hidden objects using backscattered ultra-intense laserproduced X-rays", Journal of applied Physics, Vol.114: 083103pp 1-6, 2013.

[17] Artur Andrzejczak,et.al, "Architecture of Wireless Vehicle Weight Measurement System for Structural Health Monitoring in Civil Engineering Application", International Journal of Distributed Sensor Networks, Volume 2015 (2015): May 2015.

[18] Lu Cheng, et.al, Design of a Capacitive Flexible Weighing Sensor for Vehicle WIM System “, sensors, Vol.2007 (7): 1530-1544, August 2007.

[19] Bernard Jacob, Veronique Feypell-de la Beaumelle," Improving truck safety: Potential of weigh-in-motion technology”, Science Direct, Vol.34(1): 9-15,July 2010

[20] Holger bose, eric fub, Johannes Ehrlich, "capacitive sensor mats for pressure detection with high sensitivity", AMA Conference 2015-Sensors 2015 and IR $^{2} 2015$.

\section{AUTHOR BIOGRAPHY}

Prof. K. Vidyasagar: Received B. Tech degree in Instrument Technology from Andhra University College of Engineering Visakhapatnam, M.E from P. S. G. Tech Coimbatore. He is now a research scholar under the guidance of Dr. A. Bhujangarao, Andhra University. $\mathrm{He}$ published 26 manuscripts in various national and international journals. His current research interests include image processing in biomedical instrumentation and related embedded systems.

Ms .K. Swathi: Received B. Tech degree in Electronics and Communications Engineering from Sai Spurthi Institute of technology, Sathupalli, M. Tech in Communication systems Mother Theresa Institute of Technology, Sathupalli. She published four manuscripts from various national and international journals. Her current research interests include communications related embedded systems.

Mr. K. Sudharsanarao: Received B. Tech degree in Electronics and Communications Engineering from Sai Spurthi Institute of technology, Sathupalli, M. Tech in Communication systems Mother Theresa Institute of Technology, Sathupalli. He published four manuscripts from various national and international journals. His current research interests include communications related embedded systems. 